Article

\title{
Immunomodulative Effects of Chamaecyparis obtusa Essential Oil in Mouse Model of Allergic Rhinitis
}

\author{
Seung-Heon Shin *(D), Mi-Kyung Ye, Dong-Won Lee and Mi-Hyun Che \\ Department of Otorhinolaryngology-Head and Neck Surgery, School of Medicine, Catholic University of Daegu, \\ Daegu 42472, Korea; miky@cu.ac.kr (M.-K.Y.); neck@cu.ac.kr (D.-W.L.); leonen@hanmail.net (M.-H.C.) \\ * Correspondence: hsseung@cu.ac.kr; Tel.: +82-53-650-4530
}

Received: 18 August 2020; Accepted: 30 September 2020; Published: 2 October 2020

\begin{abstract}
The present study aims to investigate the immunomodulatory effects of essential oil from Chamaecyparis obtusa (EOCO) in an ovalbumin (OVA)-induced allergic rhinitis (AR) mouse model. BALB/c mice were intraperitoneally sensitized and stimulated with OVA. From day 22 to $35,0.01 \%$ and $0.1 \%$ ECOC was intranasally administered $1 \mathrm{~h}$ before OVA stimulation. Nasal symptoms, as well as serum total and OVA-specific immunoglobulin (Ig) E levels, were measured. Interleukin (IL)-4, IL-10, interferon (IFN)- $\gamma$, and tumor necrosis factor (TNF)- $\alpha$ levels in nasal lavage fluid (NLF) and their production by activated splenocytes were measured. Histological changes in the sinonasal mucosa were evaluated through hematoxylin and eosin and periodic acid-Schiff staining procedure. Th cytokines and their transcription factor mRNA expressions were determined using reverse-transcription polymerase chain reaction. Intranasal EOCO administration significantly suppressed allergic symptoms, OVA-specific IgE level, sinonasal mucosal inflammatory cell infiltration, and mucus-producing periodic acid-Schiff (PAS) positive cell count. EOCO also significantly inhibited IL-4, IL-10, and TNF- $\alpha$ levels in NLF and activated splenocytes. Th2 and Treg related cytokines and their transcription factors in sinonasal mucosa were significantly suppressed through intransal EOCO instillation. In conclusion, repetitive EOCO intranasal instillation showed anti-inflammatory and anti-allergic effects by suppressing nasal symptoms and inhibiting the production and expression of inflammatory mediators in the OVA-induced AR mouse model.
\end{abstract}

Keywords: allergic rhinitis; essential oil; Chamaecyparis obtusa; cytokine; transcription factor

\section{Introduction}

Allergic rhinitis (AR) is the inflammation of the nasal mucosa induced by a specific immunoglobulin E (IgE)-mediated hypersensitivity reaction against inhaled allergens, which involves Th2 immune responses. Immunologic interactions between epithelial cells, lymphocytes, mast cells, interleukin (IL)-4, IL-5, IL-13, and thymic stromal lymphopoietin (TSLP) are involved in AR [1]. A large number of pharmacologic and non-pharmacologic agents have been used to alleviate the symptoms and improve the quality of life in AR patients. However, most AR treatment modalities are focused on symptomatic control with palliative effects, and allergic immunotherapy is the only potential curative therapy that influences the immunopathologic mechanism in developing nasal mucosal hypersensitivity [2].

Essential oils are volatile compounds produced by plants as a protective mechanism against harmful insects and microorganisms. Several essential oils contain active substances that exert anti-fungal, anti-oxidative, and anti-gastropathic activity [3,4]. Essential oil extracted from Chamaecyparis obtusa (EOCO) consists of several monoterpenes, sesquiterpene hydrocarbons, oxygenated sesquiterpenes, and several other substances [5,6]. EOCO is used in soap, toothpaste, and aromatic agents with anti-bacterial, anti-atopic, and anti-inflammatory effects [5,7]. Active components from Chamaecyparis obtusa were found to inhibit lipopolysaccharide-induced nitric 
oxide, prostaglandins, and inflammatory cytokine production, thereby suppressing inflammatory cell infiltration and inflammatory mediator production, as observed through in vivo and in vitro studies [3,4]. EOCO can be a promising candidate for new pharmacologic agents.

Although the biological activities of EOCO are not fully understood, it has immune modulatory properties that influence both Th1 and Th2 immune responses [8]. The effects of EOCO in AR have yet to be investigated. In the present study, we used an AR mouse model to evaluate EOCO's anti-allergic effect and its mechanism of action.

\section{Results}

\subsection{Effects of EOCO on Allergic Behaviors}

The effects of EOCO intranasal instillation on the frequency of nasal rubbing and sneezing after ovalbumin (OVA) stimulation at day 21, 28, and 35 were evaluated. OVA-stimulated mice sneezed significantly more $(27.3 \pm 8.1,28.3 \pm 7.4$, and $33.3 \pm 12.7$ at days 21,28 , and 35 , respectively) than the PBS-treated negative control mice (6.6 $\pm 2.7,8.7 \pm 2.3$, and $3.3 \pm 1.8$ at days 21,28 , and 35 , respectively). When mice were intranasally treated with triamcinolone $(16.7 \pm 3.5,16.7 \pm 6.8$, and $16.6 \pm 4.7$ at days 21,28 , and 35 , respectively) and EOCO $(13.3 \pm 5.7,15.3 \pm 4.5$, and $13.3 \pm 4.2$ with $0.01 \%$ EOCO and $16.7 \pm 6.8,15.2 \pm 7.6$, and $11.7 \pm 4.5$ with $0.1 \%$ EOCO at days 21,28 , and 35 , respectively), the frequency of sneezing was significantly decreased. The increased frequency of nasal rubbing in OVA-stimulated mice was also significantly inhibited by intranasal instillation of triamcinolone, as well as $0.01 \%$ and $0.1 \%$ EOCO (Figure 1 ).
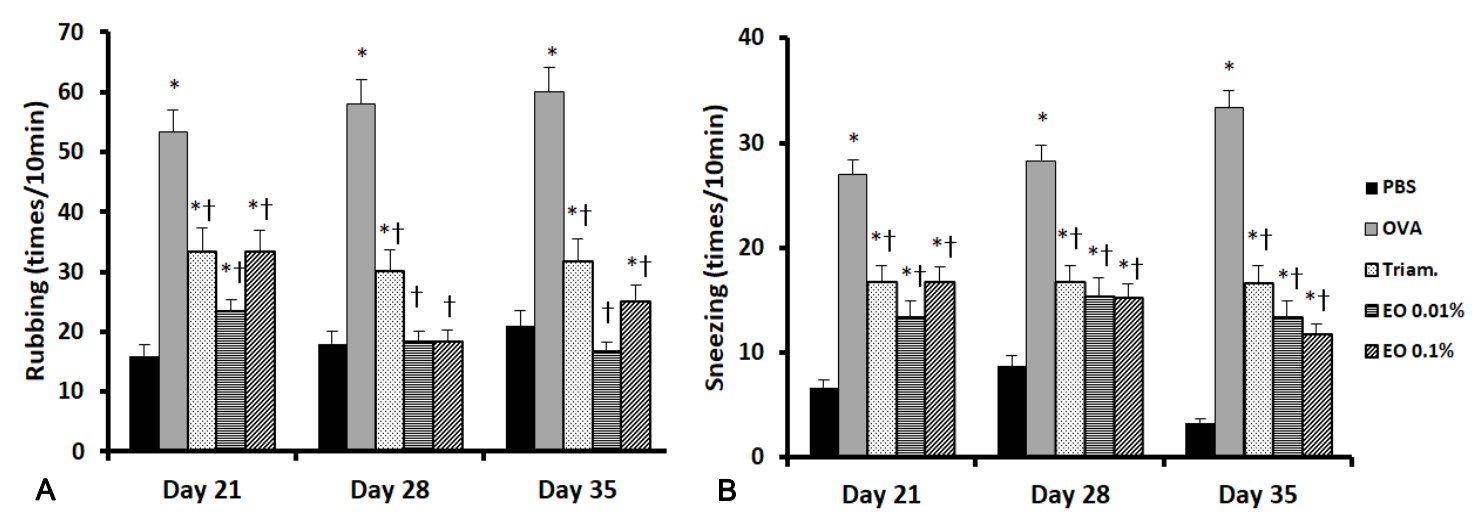

Figure 1. Effects of essential oil from Chamaecyparis obtusa (EOCO) in the allergic rhinitis mouse model ( $n=8$ mice per group). The frequency of nasal rubbing (A) and sneezing (B) counts was significantly decreased with intranasal instillation of triamcinolone (Triam.) and EOCO. PBS, phosphate-buffered saline; OVA, ovalbumin; * $(p<0.05)$ versus the PBS group; $+(p<0.05)$ versus the OVA group.

\subsection{Effects of EOCO on Total Serum IgE and OVA-Specific IgE Levels}

The anti-allergic effects of EOCO on the immune response in AR mice were determined by measuring the total and OVA-specific IgE levels using enzyme-linked immunosorbent assay (ELISA) kits. The levels of total serum IgE and OVA-specific IgE after OVA stimulation $(18,230.2 \pm 2330.1 \mathrm{pg} / \mathrm{mL}$ and $21.3 \pm 3.8 \mathrm{pg} / \mathrm{mL}$, respectively) were markedly elevated, compared with those in the negative control $(1202.3 \pm 272.2 \mathrm{pg} / \mathrm{mL}$ and $1.8 \pm 2.7 \mathrm{pg} / \mathrm{mL}$, respectively) group. When mice were treated with triamcinolone, the total IgE and OVA-specific $\operatorname{IgE}$ were significantly inhibited. However, $0.01 \%$ and $0.1 \%$ EOCO only suppressed OVA-specific IgE, but not the total IgE (Figure 2). 

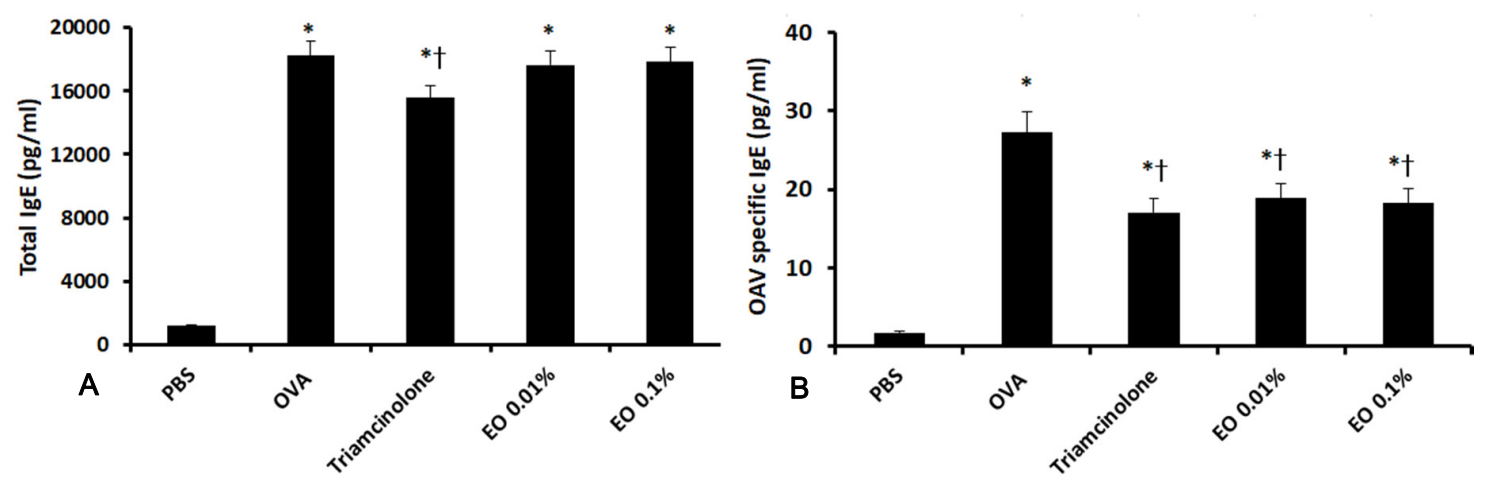

Figure 2. Effects of essential oil from Chamaecyparis obtusa (EOCO) on total serum IgE (A) and ovalbumin (OVA)-specific IgE (B) level ( $\mathrm{n}=8$ mice per group). Triamcinolone suppressed both total serum IgE and OVA-specific IgE levels, whereas EOCO only suppressed OVA-specific IgE level. PBS, phosphate-buffered saline; OVA, ovalbumin; * $(p<0.05)$ versus the PBS group; $\dagger(p<0.05)$ versus the OVA group.

\subsection{Effects of EOCO on the Inflammatory Mediator Levels in Nasal Lavage Fluid (NLF)}

IL-4, IL-10, IFN- $\gamma$, and TNF- $\alpha$ in NLF were measured. The levels of IL-4 (12.3 $\pm 5.2 \mathrm{pg} / \mathrm{mL})$, IL-10 $(9.2 \pm 3.5 \mathrm{pg} / \mathrm{mL})$, IFN- $\gamma(5.1 \pm 2.7 \mathrm{pg} / \mathrm{mL})$, and TNF- $\alpha(7.0 \pm 3.2 \mathrm{pg} / \mathrm{mL})$ in the NLF were significantly greater in OVA-stimulated mice than those in the negative control mice (IL-4, $4.1 \pm 2.5 \mathrm{pg} / \mathrm{mL}$; IL-10, 4.6 $\pm 3.2 \mathrm{pg} / \mathrm{mL} ; \mathrm{IFN}-\gamma, 2.7 \pm 2.1 \mathrm{pg} / \mathrm{mL}$; and TNF- $\alpha, 5.3 \pm 3.6 \mathrm{pg} / \mathrm{mL}$ ). The levels of IL-4, IL-10, and TNF- $\alpha$ were significantly decreased by intranasal instillation of triamcinolone and $\mathrm{EOCO}$, compared with those in OVA-sensitized mice. However, IFN- $\gamma$ level in the NLF was only significantly influenced by intranasal instillation of $0.01 \%$ EOCO $(2.5 \pm 1.7 \mathrm{pg} / \mathrm{mL})$, compared with OVA-stimulated mice (Table 1).

Table 1. Effects of essential oil from Chamaecyparis obtusa (EOCO) on the level of inflammatory mediators in the nasal lavage fluid (NLF) ( $\mathrm{n}=8$ mice per group).

\begin{tabular}{cccccc}
\hline & NC & OVA & Triamcinolone & EOCO 0.01\% & EOCO 0.1\% \\
\hline IL-4 $(\mathrm{pg} / \mathrm{mL})$ & $4.08 \pm 2.46$ & $12.28 \pm 5.24^{\mathrm{a}}$ & $8.22 \pm 2.23^{\mathrm{a}, \mathrm{b}}$ & $7.35 \pm 1.45^{\mathrm{a}, \mathrm{b}}$ & $5.58 \pm 1.65^{\mathrm{b}}$ \\
IFN-r $(\mathrm{pg} / \mathrm{mL})$ & $2.65 \pm 2.13$ & $5.06 \pm 2.65^{\mathrm{a}}$ & $4.41 \pm 0.68$ & $2.50 \pm 1.65^{\mathrm{b}}$ & $4.55 \pm 1.45$ \\
IL-10 $(\mathrm{pg} / \mathrm{mL})$ & $4.58 \pm 3.21$ & $9.16 \pm 3.48^{\mathrm{a}}$ & $2.86 \pm 0.77^{\mathrm{b}}$ & $3.33 \pm 1.36^{\mathrm{b}}$ & $6.58 \pm 1.82 \mathrm{~b}^{\mathrm{a}}$ \\
TNF-a $(\mathrm{pg} / \mathrm{mL})$ & $5.29 \pm 3.57$ & $7.02 \pm 3.22$ & $5.81 \pm 1.82^{\mathrm{b}}$ & $5.40 \pm 1.86^{\mathrm{b}}$ & $5.35 \pm 0.60^{\mathrm{b}}$ \\
\hline
\end{tabular}

$\mathrm{NC}$, negative control; OVA, ovalbumin; ${ }^{\mathrm{a}} p<0.05$, significantly different from the NC group; ${ }^{\mathrm{b}} p<0.05$, significantly different from the OVA group.

\subsection{Effects of EOCO on the Inflammatory Mediator Production from Splenocytes}

Isolated mouse splenocytes were stimulated with OVA for $72 \mathrm{~h}$. The splenocytes of allergic mice produced larger amounts of IL-4 $(15.0 \pm 5.3 \mathrm{pg} / \mathrm{mL}), \mathrm{IL}-10(20.2 \pm 7.5 \mathrm{pg} / \mathrm{mL}), \mathrm{IFN}-\gamma(10.5 \pm 5.4 \mathrm{pg} / \mathrm{mL})$, and TNF- $\alpha(305.2 \pm 86.7 \mathrm{pg} / \mathrm{mL})$ after OVA stimulation. IL-4 production was significantly suppressed by triamcinolone $(9.4 \pm 3.6 \mathrm{pg} / \mathrm{mL})$ and $0.1 \% \mathrm{EOCO}(9.0 \pm 2.7 \mathrm{pg} / \mathrm{mL})$. IL-10 production was significantly suppressed by $0.01 \%(13.8 \pm 5.2 \mathrm{pg} / \mathrm{mL})$ and $0.1 \%(15.5 \pm 6.3 \mathrm{pg} / \mathrm{mL})$ EOCO, and TNF- $\alpha$ was only significantly inhibited by $0.1 \%$ EOCO $(237.8 \pm 112.3 \mathrm{pg} / \mathrm{mL})$. However, the increased production of IFN- $\gamma$ by OVA stimulation was not inhibited by the triamcinolone and EOCO treatments (Table 2). 
Table 2. Effects of essential oil from Chamaecyparis obtusa (EOCO) on the production of inflammatory mediators by splenocytes after stimulation with $100 \mu \mathrm{g} / \mathrm{mL}$ of ovalbumin (OVA) ( $\mathrm{n}=8$ mice per group).

\begin{tabular}{cccccc}
\hline & NC & OVA & Triamcinolone & EOCO 0.01\% & EOCO 0.1\% \\
\hline IL-4 & $5.47 \pm 1.45$ & $14.95 \pm 5.34^{\mathrm{a}}$ & $9.43 \pm 3.56^{\mathrm{a}, \mathrm{b}}$ & $15.55 \pm 4.74^{\mathrm{a}}$ & $9.02 \pm 2.72^{\mathrm{a}, \mathrm{b}}$ \\
IFN-r & $6.85 \pm 2.52$ & $10.48 \pm 5.37^{\mathrm{a}}$ & $8.70 \pm 5.12^{\mathrm{a}}$ & $9.16 \pm 2.86^{\mathrm{a}}$ & $8.39 \pm 2.94^{\mathrm{a}}$ \\
IL-10 & $6.86 \pm 1.60$ & $20.20 \pm 7.47^{\mathrm{a}}$ & $25.93 \pm 7.71^{\mathrm{a}}$ & $13.84 \pm 5.21^{\mathrm{a}, \mathrm{b}}$ & $15.52 \pm 6.33^{\mathrm{a}, \mathrm{b}}$ \\
TNF-a & $134.69 \pm 57.45$ & $305.18 \pm 86.73^{\mathrm{a}}$ & $302.52 \pm 60.24^{\mathrm{a}}$ & $288.18 \pm 78.54^{\mathrm{a}}$ & $237.81 \pm 112.34^{\mathrm{a}, \mathrm{b}}$ \\
\hline
\end{tabular}

$\mathrm{NC}$, negative control; OVA, ovalbumin; ${ }^{\mathrm{a}} p<0.05$, significantly different from the NC group; ${ }^{\mathrm{b}} p<0.05$, significantly different from the OVA group.

\subsection{Effects of EOCO on the Expression of Inflammatory Mediators and Transcription Factors in the Sinonasal Mucosa}

We performed real-time RT-PCR to determine the influence of EOCO intranasal instillation on the expression of cytokines and their transcription factor mRNAs in the sinonasal mucosa. IL-4 and GATA-3, IL-10 and Foxp3, and T-bet mRNA expressions were significantly increased in allergic mice. IL-4 and GATA-3 expressions, as well as IL-10 and Foxp3 mRNA expressions, were significantly inhibited by intranasal instillation of triamcinolone and EOCO. Although IFN $-\gamma$ mRNA expression was not significantly different among the five groups, T-bet mRNA expressions were significantly inhibited by triamcinolone and $0.1 \%$ EOCO (Figure 3).
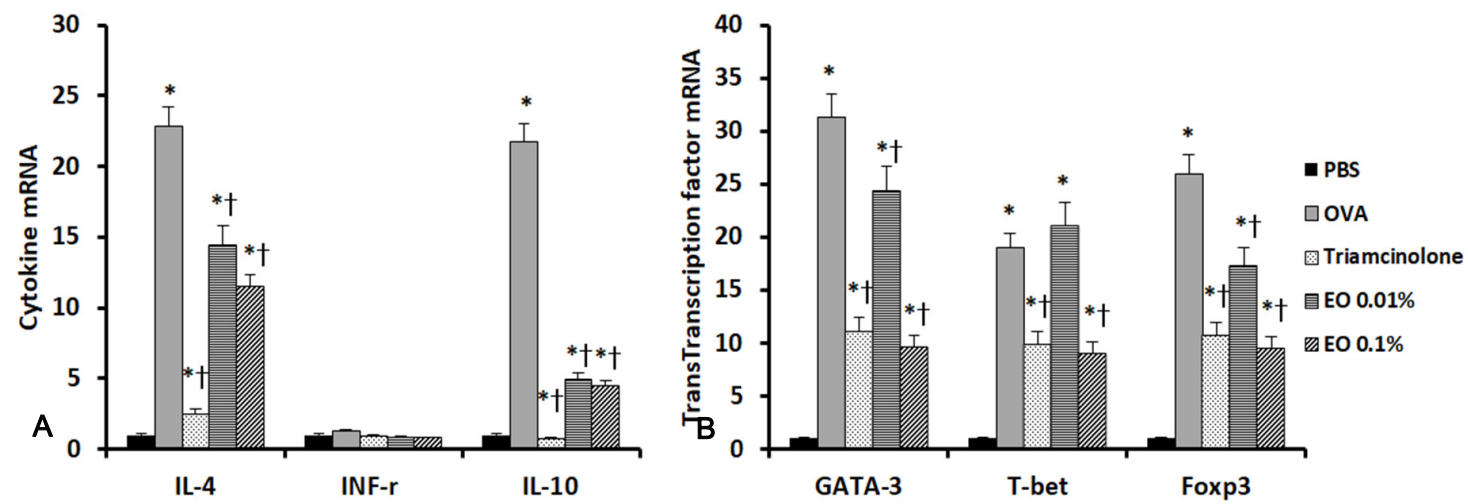

Figure 3. Effects of essential oil from Chamaecyparis obtusa (EOCO) on the expression of inflammatory mediator (A) and transcription factor mRNAs (B) in the sinonasal mucosa ( $n=4$ mice per group). IL-4 and IL-10, as well as their transcription factor mRNAs' expressions, were significantly inhibited by intrannasal EOCO instillation. PBS, phosphate-buffered saline; OVA, ovalbumin; ${ }^{*} p<0.05$ versus the PBS group; $+p<0.05$ versus the OVA group.

\subsection{Effects of EOCO on Sinonasal Mucosal Inflammation}

Intranasal OVA stimulation $(2.2 \pm 0.6)$ significantly increased inflammatory cell infiltration compared with untreated negative control mice $(0.5 \pm 0.4)$. Intranasal instillation of triamcinolone $(1.6 \pm 0.5)$ and EOCO (1.4 \pm 0.8 for $0.01 \%$ EOCO and $1.3 \pm 0.8$ for $0.1 \%$ EOCO) significantly suppressed inflammatory cell infiltration, compared with OVA-stimulated mice. Eosinophil infiltration was also significantly inhibited by intranasal instillation of triamcinolone $(13.8 \pm 5.2)$ and EOCO $(29.5 \pm 13.7$ for $0.01 \%$ EOCO and $25.0 \pm 9.4$ for $0.1 \%$ EOCO), compared with untreated mice ( $44.0 \pm 15.6)$. Periodic acid-Schiff (PAS)-positive goblet cells in the sinonasal mucosa showed a significant increases in OVA-stimulated mice (64.0 \pm 16.4$)$, compared with the control mice $(6.4 \pm 2.8)$. Intranasal instillation of triamcinolone $(49.9 \pm 21.7)$ and EOCO ( $45.4 \pm 16.2$ for $0.01 \%$ EOCO and $43.3 \pm 19.4$ for $0.1 \%$ EOCO) significantly influenced the number of PAS-positive cells. However, the increased thickness of epithelial cells in the sinonasal mucosa in OVA-stimulated mice was not influenced by intranasal instillation of triamcinolone or EOCO (Figure 4). 
A

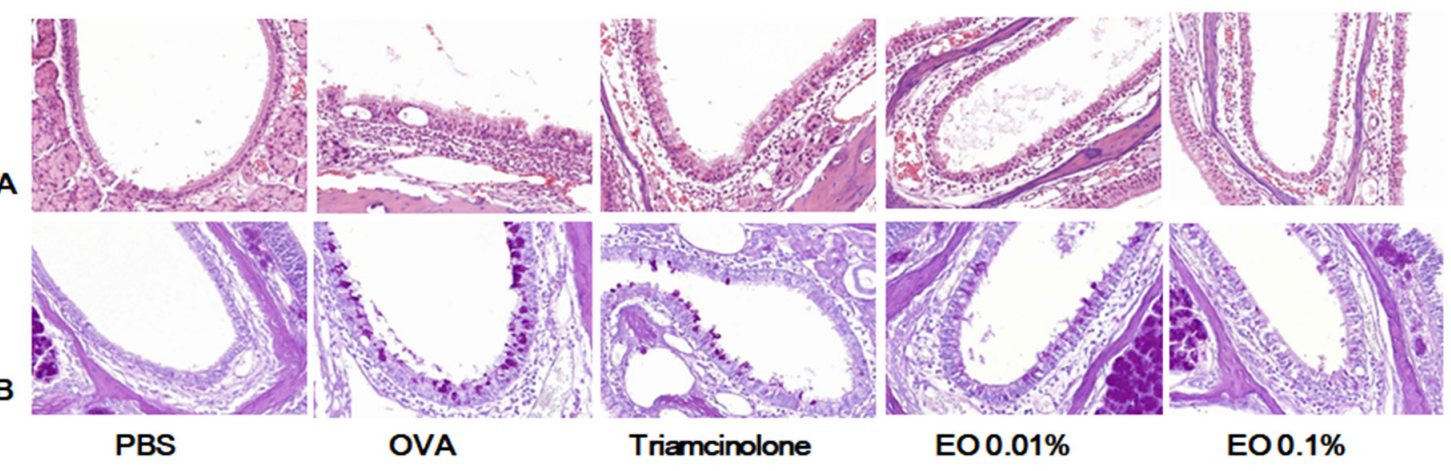

C
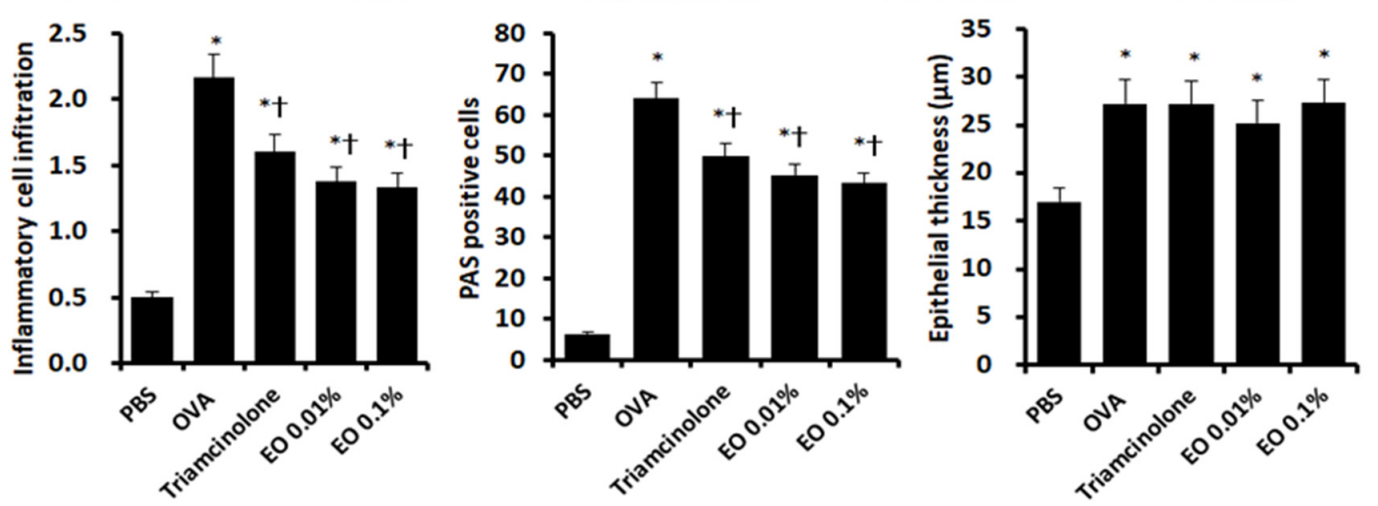

Figure 4. Effects of essential oil from Chamaecyparis obtusa (EOCO) on the histologic characteristics of sinonasal mucosa ( $\mathrm{n}=4$ mice pergroup). Inflammatory cell infiltration and periodic acid-Schiff (PAS)-positive cells were significantly decreased by intrannasal EOCO instillation (C). A, representative photographs of hematoxylin and eosin (H\&E) stained tissues; $\mathbf{B}$, representative photographs of PAS stained tissues; PBS, phosphate-buffered saline; OVA, ovalbumin; ${ }^{*} p<0.05$ versus the PBS group; $+p<0.05$ versus the OVA group.

\section{Discussion}

$\mathrm{AR}$ is an immediate type I hypersensitivity reaction, characterized by the recruitment of inflammatory cells, increased pro-inflammatory mediators, and Th2 cytokines in the sinonasal mucosa. Inflammatory symptoms are mainly triggered by inflammatory mediators, such as histamine; IL-4; IL-6; and several other inflammatory mediators produced by inflammatory cells, such as mast cells, eosinophils, basophils, and T lymphocytes [9]. Several pharmacologic and immunologic agents are used to control allergic symptoms [10]. Additional new promising pharmacologic and immunologic approaches will certainly change the pattern of the treatment modalities for AR, although most of the therapeutic agents used in treating AR are effective and safe. In the present study, EOCO showed anti-inflammatory and anti-allergic effects in an AR mouse model.

C. obtusa is a tropical tree species commonly found in Japan and the southern region of Korea. EOCO contains a large amount of phytoncides, a natural antibiotic volatile compound that protect plants from harmful insects, animals, or microorganisms. EOCO contains several types of monoterpenes, sesquiterpene hydrocarbons, oxygenated sesquiterpenes, and several others substances. EOCO has been reported to reduce the production of prostaglandin E2, TNF- $\alpha$, and cyclo-oxygenase-2, with anti-microbial, anti-fungal, anti-oxidative, and anti-inflammatory properties [11-13]. We used microencapsulated essential oil for the present study, because essential oils are volatile and hydrophobic. This microencapsulation protects active compounds from environmental factors, such as oxygen, light, and moisture, and increases their solubility in water [8,14]. Stylene maleic anhydride polymer is a synthetic polymer that is used in microencapsule formation through interfacial polycondensation or complex coacervation.

The results of the present study showed the anti-inflammatory and anti-allergic effects of EOCO in an AR mouse model. Allergic symptoms mainly originated from inflammatory cells in response to 
inflammatory cells-derived mediators [15]. Topical blockage of TNF- $\alpha$ reduced pathologic allergic reaction in the sinonasal mucosa of AR mice [16]. Intranasal instillation of EOCO significantly suppressed IL-4, IL-10, and TNF- $\alpha$ levels in the NLF, with decreased AR symptoms. Although IL-4 and IL-10 mRNA expressions were more strongly suppressed by triamcinolone, $0.01 \%$ and $0.1 \%$ of EOCO also significantly suppressed these mRNAs' expressions. Triamcinolone and EOCO suppressed IL-4and IL-10-related transcription factors. EOCO suppressed the expression of T-bet, an IFN- $\gamma$ related transcription factor. However, EOCO did not influence IFN- $\gamma$ mRNA expression. This discrepancy may be related to the low IFN- $\gamma$ mRNA expression level in the AR mouse model. The IFN- $\gamma$ level in the NLF tended to be decreased by EOCO, although we did not measure IFN- $\gamma$ protein level in the sinonasal mucosa. Intranasal EOCO instillation influenced Th2 and Treg immune responses in the AR mouse model and the anti-inflammatory potency was very similar to triamcinolone. In the present study, however, we cannot draw a direct conclusion of whether or not EOCO could influence Th1 immune response.

Serum total and OVA-specific IgE levels were significantly increased in OVA-stimulated mice. As an exogenous antigen, OVA stimulates B cells to produce IgE and activate mast cells [17]. Intranasal instillation of EOCO suppressed the serum OVA-specific IgE level, but did not influence the total serum IgE level. However, OVA-specific IgE levels in EOCO-treated mice were much higher than those of negative control mice. The IL-4, IL-10, and TNF- $\alpha$ levels in the NLF were significantly low in both $0.01 \%$ and $0.1 \%$ EOCO-treated mice compared with those in OVA-stimulated mice. When splenocytes were stimulated with OVA, IL-4, IL-10, and TNF- $\alpha$ production significantly increased in OVA-stimulated mice, and the production of these inflammatory mediators was decreased in the splenocytes of mice that were intranasally treated with $0.1 \%$ EOCO. Intranasal EOCO instillation may more strongly modulate local inflammatory responses than systemic inflammatory responses, although we cannot draw a conclusion from the results of the present study. If we measured OVA-specific IgE in the NLF, it might appear to be as low as that in negative control mice. These findings indicate that intranasal EOCO instillations may effectively inhibit local inflammation with only few systemic effects using higher concentrations of EOCO.

Inflammatory cell infiltration and mucus hypersecretion are pathognomonic characteristics of airway inflammatory diseases. Tissue eosinophilia plays a crucial role in AR. The OVA-induced allergic mouse model showed increased inflammatory cell infiltration with tissue eosinophilia. Inflammatory cell infiltration was downregulated by EOCO, and the increased eosinophil count was significantly suppressed through intranasal instillation of triamcinolone $(68.6 \%)$ and EOCO $(33.0 \%$ for $0.01 \%$ EOCO and $43.2 \%$ for $0.1 \%$ EOCO). Pro-inflammatory cytokines, including IL-6 and IL-8, have been known as major cytokines involved in mucus hypersecretion and AR pathogenesis [18]. Intranasal EOCO instillation suppressed mucus-producing cells in the sinonasal mucosa. On the basis of these results, EOCO inhibits mucus production by suppressing the production of pro-inflmmatory mediators in an AR mouse model.

\section{Materials and Methods}

\subsection{Preparation of Microencapsulated EOCO}

Qwell Inc. (Seoul, Korea) kindly provided microencapsulated EOCO. Essential oil was extracted from leaves of C. obtusa collected in Masan, Kyunsangnamdo, Korea. EOCO was produced through steam distillation of leaves according to previously described methods [9]. The collected essential oil was stored at room temperature in nitrogen tanks for 1 year to stabilize its components and be suitable for daily products. The nitrogen tank prevents the evaporation and composition change of EOCO. The composition of EOCO was determined using a gas chromatography mass spectrometry analysis (Agilent Tech., Santa Clara, CA, USA). Essential oil contained more than 20 components and Table 3 shows the main chemical composition of ECOC used in this study. For microencapsulation, EOCO was mixed with a water-soluble stylene maleic anhydride polymer, and melanin pre-condensate was 
added to the mixture, resulting in the formation of microcapsules consisting of a spherical inner core and an outer shell.

Table 3. Main components of essential oil from Chamaecyparis obtusa.

\begin{tabular}{cccc}
\hline Compound & Kovatz Index & Retention Time (min) & Peak Area (\%) \\
\hline$\alpha$-Pinene & 928 & 8.75 & 5.96 \\
Sabinene & 966 & 10.96 & 16.72 \\
Myrcene & 989 & 11.36 & 19.45 \\
$\alpha$-Terpinene & 1017 & 12.69 & 3.05 \\
$\gamma$-Terpinene & 1044 & 13.54 & 4.75 \\
Limonene & 1028 & 13.76 & 1.82 \\
Terepineol & 1095 & 15.21 & 1.26 \\
Terpinene-4-ol & 1162 & 16.23 & 2.82 \\
Bornyl acetate & 1265 & 27.53 & 9.46 \\
$\alpha$-Terpinyl acetate & 1349 & 28.64 & 15.69 \\
\hline
\end{tabular}

\subsection{Preparation of OVA-Induced AR Mouse Model}

Pathogen-free female BALB/c mice (aged 6-8 weeks) were obtained from Hyosung Science Inc. (Daegu, Korea). They were kept under specific pathogen-free conditions. This study was conducted in accordance with the guidelines of the National Institute of Health and approved by the Institutional Review Board of Animal Experiments of Daegu Catholic University Medical Center.

Mice were sensitized through intraperitoneal injection with $75 \mu \mathrm{g}$ of OVA in $200 \mu \mathrm{L}$ of phosphate-buffered saline (PBS) containing $2 \mathrm{mg}$ of aluminum hydroxide (Sigma-Aldrich, St. Louis, MO, USA) on days $0,7,14$, and 21. On days 22-35 after initial sensitization, mice were stimulated through bilateral intranasal instillation with $500 \mu \mathrm{g}$ of OVA in $20 \mu \mathrm{L}$ of PBS. The mice were randomly divided into five groups $(n=8)$. The negative control mice were stimulated with PBS instead of OVA (group I). To determine the anti-allergic and anti-inflammatory effect of EOCO, $20 \mu \mathrm{L}$ of $0.01 \%$ (group IV) and $0.1 \%$ (group V) EOCO dissolved in PBS was intranasally instilled using a micropipette $1 \mathrm{~h}$ before each stimulation on days 22-35. The control group was treated with PBS (group II) or $0.5 \mathrm{mg} / \mathrm{kg}$ of triamcinolone (group III).

\subsection{Evaluation of Nasal Symptoms}

The frequency of nasal rubbing and sneezing was recorded during a period of $15 \mathrm{~min}$ after stimulation on days 21,28 , and 35 , and the results of each group were compared.

\subsection{Evaluation of Nasal Lavage Fluid (NLF)}

NLF was collected $24 \mathrm{~h}$ after the last intranasal stimulation at day 35. A 21-gauge catheter was inserted through a partial tracheal resection site in the direction of the upper airway and into the nasopharynx. The nasal cavity was gently perfused with $1 \mathrm{~mL}$ of cold PBS. The collected NLF was centrifuged at $2000 \mathrm{rpm}$ for $7 \mathrm{~min}$ at $4{ }^{\circ} \mathrm{C}$. The amount of interleukin (IL)-4, IL-10, interferon (IFN)- $\gamma$, and tumor necrosis factor (TNF)- $\alpha$ in the NLF was determined using enzyme-linked immunosorbent assay (ELISA) kits (R\&D Systems, Minneapolis, MN, USA).

\subsection{Measurement of Serum $\operatorname{IgE}$}

Blood samples were collected from the inferior vena cava $24 \mathrm{~h}$ after the last intranasal stimulation. Serum was obtained by centrifugation, and total and OVA-specific IgE were measured using ELISA kits (Pharmingen, San Diego, CA, USA). 


\subsection{Measurement of Cytokines and Transcription Factor mRNAs in the Sinonasal Mucosa}

Total RNA was extracted from the sinonasal mucosa using Trizol reagent (Invitrogen, Carlsbad, CA, USA). RNA purity and concentration were measured through spectrophotometery (Beckman, Mountain View, CA, USA). Complementary DNA was made from $1 \mu \mathrm{g}$ of RNA through reverse-transcription polymerase chain reaction (RT-PCR) amplification with a thermal cycler (PerkinElmer Corp., Norwalk, CT, USA). From the amplified cDNA, the quantitative PCR was performed using a SYBR Green PCR core kit (PE Applied Biosystems, Foster City, CA, USA). The primer sequences and amplification products were as follows: IL-4 sense 5' - CAATTGCAATGCCATCTACAGGAC-3' and antisense 5'-TTTTGGTATCGGGGAGGCTG-3' (104 bp); IL-10 sense 5'-GCCAGAGCCACATGCTCCTA-3' and antisense 5'-GATAAGGCTTGGCAACCCAAGTAA-3' (145 bp); IFN- $\gamma$ sense 5'-CGGCACAG TCATTGAAAGCCTA-3' and antisense 5'-GTTGCTGATGGCCTGATTGTC-3' (199 bp); T-bet sense 5'-GCCAGGGAACCGCTTATA-3' and antisense 5'-CCTTGTTGTTGGTGAGCTTTA-3' (104 bp); GATA-3 sense 5'-TACCACCTATCCGCCCTATG-3' and antisense 5'-GCCTCGAC TTACATCCGAAC-3' (101 bp); Foxp3 sense 5'-CACCTATGCCACCCTTATCCG-3' and antisense 5'-CATGCGAGTAAACCAATGGTAGA-3' (91 bp); and to $\beta$-actin sense 5'-GCAGAAGGA GATTACTGCTCT-3' and antisense 5'-GCTGATCCACATCTGCTGGAA-3' (136 bp). Initial denaturation was performed at $95^{\circ} \mathrm{C}$ for $2 \mathrm{~min}$, followed by 40 cycles consisting of denaturation at $94{ }^{\circ} \mathrm{C}$ for $10 \mathrm{~s}$, annealing at $60^{\circ} \mathrm{C}$ for $10 \mathrm{~s}$, and elongation at $72{ }^{\circ} \mathrm{C}$ for $45 \mathrm{~s}$. All samples were amplified in triplicate. The expression levels of the aformentioned mRNA were normalized to the median value for $\beta$-actin and expression levels were measured using the cycle threshold method $\left(2^{-\Delta \Delta} \mathrm{CT}\right)$.

\subsection{Measurement of Cytokines from Splenocytes with OVA}

Splenocytes were isolated from spleen tissues by grounding and separating the tissue into single cells using a $70 \mu \mathrm{m}$ cell strainer. Red blood cells (RBCs) were removed using an RBC lysis buffer (BioLegend, San Diego, CA, USA). The splenocytes were incubated in Roswell Park Memorial Institute 1640 medium supplemented with $10 \%$ fetal bovine serum, $100 \mathrm{U} / \mathrm{mL}$ of penicillin, and $100 \mu \mathrm{g} / \mathrm{mL} \mathrm{of}$ streptomycin (Gibco, Grand Island, NY, USA). After stimulation with $100 \mu \mathrm{g} / \mathrm{mL}$ of OVA for $72 \mathrm{~h}$, the supernatant was collected, and IL-4, IL-10, IFN- $\gamma$, and TNF- $\alpha$ levels were measured using ELISA kits (R\&D Systems).

\subsection{Histologic Evaluation of Sinonasal Mucosa}

Mice were anesthetized with $1 \%$ pentobarbital sodium and painlessly sacrificed $24 \mathrm{~h}$ after the last intranasal stimulation at day 36. The specimens were decalcified in ethylenediaminetetraacetic acid and then immersed in $4 \%$ paraformaldehyde for $24 \mathrm{~h}$. The paraffin embedded tissue was anteroposterioly sectioned at a $5 \mu \mathrm{m}$ thickness, and three anatomically similar sections were chosen from each mouse for analysis [19].

Inflammatory cell infiltration and epithelial thickness were quantified in hematoxylin and eosin (H\&E) stained sections. Eosinophil infiltration was calculated as the average number of cells in five high power fields. The degree of submucosal inflammatory cell infiltration was quantified into four categories as follows: 0 , none; 1 , mild occasional scattered inflammatory cells; 2, moderate; and 3, severe diffuse infiltration of inflammatory cells. Goblet cell hyperplasia was determined by periodic acid-Schiff (PAS) staining, and the average number of goblet cells was counted using an eyepiece reticle at $\times 200$ magnification. Epithelial thickness was directly measured at $\times 400$ magnification through a video camera (Olympus Optical Co. Ltd., Tokyo, Japan) and analyzed using the DP Controller software (ver. 2.2.1.227). All tissue sections were blindly examined in terms of tissue origin, and the mean counts were determined at three different mucosal areas for each of the three sections per mouse. 


\subsection{Statistical Analysis}

All measured parameters are expressed as mean \pm standard deviation of eight representative independent experiments for each group. The comparison between two groups was analyzed using Student's t-test and data among several groups were analyzed by one-way analysis of variance (ANOVA) followed by Tukey's test for normally distributed data. The Mann-Whitney $U$ test and the Kruskal-Wallis test with post-hoc Bonferroni-Dunn test were performed for non-normally distributed data using the SPSS ver. 21 software (IBM Corp., Armonk, NY, USA). A $p$-value of $<0.05$ was considered statistically significant.

\section{Conclusions}

Repetitive intranasal EOCO instillation resulted in anti-inflammatory and anti-allergic effects, with the suppression of nasal symptoms by inhibiting the production and expression of inflammatory mediators in the OVA-induced AR mouse model. Intranasal EOCO instillation more strongly suppressed local inflammatory responses and elicited weaker systemic effects. The anti-inflammatory and anti-allergic effect of EOCO was very similar with triamcinolone, which is the representative glucocorticosteroid. These findings suggest that EOCO could be a good candidate for the production of a local anti-inflammatory and anti-allergic agent with low systemic side effects.

Author Contributions: Conceptualization, S.-H.S.; methodology, M.-H.C.; validation, formal analysis, and data curation, S.-H.S. and M.-K.Y.; writing —original draft preparation, S.-H.S. and D.-W.L.; writing-review and editing, M.-K.Y.; funding acquisition, S.-H.S. All authors have read and agreed to the published version of the manuscript.

Funding: This research was supported by Basic Science Research Program through the National Research Foundation of Korea (NRF) funded by the Ministry of Education (2016R1D1A1B03931622).

Acknowledgments: The authors wish to thank Jae-Won Jang (Qwell Inc., Seoul, Korea) for providing microencapsulated essential oil for this study.

Conflicts of Interest: The authors declare no conflict of interest.

\section{References}

1. Bernstein, D.I.; Schwartz, G.; Bernstein, J.A. Allergic Rhinitis: Mechanisms and Treatment. Immunol. Allergy Clin. N. Am. 2016, 36, 261-278. [CrossRef]

2. May, J.R.; Dolen, W.K. Management of Allergic Rhinitis: A Review for the Community Pharmacist. Clin. Ther. 2017, 39, 2410-2419. [CrossRef] [PubMed]

3. Park, Y.; Jung, S.M.; Yoo, S.A.; Kim, W.U.; Cho, C.S.; Park, B.J.; Woo, J.M.; Yoon, C.H. Antinociceptive and anti-inflammatory effects of essential oil extracted from Chamaecyparis obtusa in mice. Int. Immunopharmacol. 2015, 29, 320-325. [CrossRef] [PubMed]

4. Ahn, C.; Lee, J.H.; Kim, J.W.; Park, M.J.; Lee, S.S.; Jeung, E.B. Alleviation effects of natural volatile organic compounds from Pinus densiflora and Chamaecyparis obtusa on systemic and pulmonary inflammation. Biomed. Rep. 2018, 9, 405-414. [CrossRef] [PubMed]

5. Bae, D.; Seol, H.; Yoon, H.G.; Na, J.R.; Oh, K.; Choi, C.Y.; Lee, D.W.; Jun, W.; Youl Lee, K.; Lee, J.; et al. Inhaled essential oil from Chamaecyparis obtuse ameliorates the impairments of cognitive function induced by injection of beta-amyloid in rats. Pharm. Biol. 2012, 50, 900-910. [CrossRef] [PubMed]

6. Bae, M.S.; Park, D.H.; Choi, C.Y.; Kim, G.Y.; Yoo, J.C.; Cho, S.S. Essential Oils and Non-volatile Compounds Derived from Chamaecyparis obtusa: Broad Spectrum Antimicrobial Activity against Infectious Bacteria and MDR(multidrug resistant) Strains. Nat. Prod. Commun. 2016, 11, 693-694. [CrossRef]

7. Yang, H.; Ahn, C.; Choi, I.G.; Choi, W.S.; Park, M.J.; Lee, S.S.; Choi, D.H.; Jeung, E.B. Estimation of the environmental effect of natural volatile organic compounds from Chamaecyparis obtusa and their effect on atopic dermatitis-like skin lesions in mice. Mol. Med. Rep. 2015, 12, 345-350. [CrossRef] [PubMed]

8. Shin, S.H.; Ye, M.K.; Lee, D.W.; Che, M.H. Effect of microencapsulated essential oil form Chamaecyparis obtusa on monocyte-derived dendritic cell activation and CD4 ${ }^{+} \mathrm{T}$ cell polarization. PLoS ONE 2018, 13, e0201233. [CrossRef] [PubMed] 
9. Lee, G.S.; Hong, E.J.; Gwak, K.S.; Park, M.J.; Choi, K.C.; Choi, I.G.; Jang, J.W.; Jeung, E.B. The essential oils of Chamaecyparis obtusa promote hair growth through the induction of vascular endothelial growth factor gene. Fitoterapia 2010, 81, 17-24. [CrossRef] [PubMed]

10. Shin, S.H.; Kim, Y.H.; Kim, J.K.; Park, K.K. Anti-allergic effect of bee venom in an allergic rhinitis mouse model. Biol. Pharm. Bull. 2014, 37, 1295-1300. [CrossRef] [PubMed]

11. Kakli, H.A.; Riley, T.D. Allergic Rhinitis. Prim. Care 2016, 43, 465-475. [CrossRef] [PubMed]

12. Meng, Y.; Wang, C.; Zhang, L. Recent developments and highlights in allergic rhinitis. Allergy 2019, 74, 2320-2328. [CrossRef] [PubMed]

13. Park, Y.; Yoo, S.A.; Kim, W.U.; Cho, C.S.; Woo, J.M.; Yoon, C.H. Anti-inflammatory effects of essential oils extracted from Chamaecyparis obtusa on murine models of inflammation and RAW 264.7 cells. Mol. Med. Rep. 2016, 13, 3335-3341. [CrossRef] [PubMed]

14. Kwak, B.M.; Kim, E.H.; Kim, Y.M.; Kim, H.T. Component analysis of four-part extracts from Chamaecyparis obtusa Endl. by supercritical fluid extraction and anti-inflammatory effect on RAW 264.7cells. J. Exerc. Rehabil. 2019, 15, 723-730. [CrossRef] [PubMed]

15. Raha, S.; Kim, S.M.; Lee, H.J.; Lee, S.J.; Heo, J.D.; Venkatarame Gowda Saralamma, V.; Ha, S.E.; Kim, E.H.; Mun, S.P.; Kim, G.S. Essential oil from Korean Chamaecyparis obtusa leaf ameliorates respiratory activity in SpragueDawley rats and exhibits protection from NF-kappaB-induced inflammation in WI38 fibroblast cells. Int. J. Mol. Med. 2019, 43, 393-403. [CrossRef] [PubMed]

16. Carvalho, I.T.; Estevinho, B.N.; Santos, L. Application of microencapsulated essential oils in cosmetic and personal healthcare products-a review. Int. J. Cosmet. Sci 2016, 38, 109-119. [CrossRef]

17. Shi, Z.; Jiang, W.; Wang, M.; Wang, X.; Li, X.; Chen, X.; Qiao, L. Inhibition of JAK/STAT pathway restrains TSLP-activated dendritic cells mediated inflammatory $\mathrm{T}$ helper type 2 cell response in allergic rhinitis. Mol. Cell. Biochem. 2017, 430, 161-169. [CrossRef]

18. Zhang, Z.; Kang, H. Protective effect of Asarum sieboldii essential oil on ovalbumin induced allergic rhinitis in rat. Biosci. Rep. 2020, 26, BSR20191370. [CrossRef]

19. Fu, M.; Fu, S.; Ni, S.; Zou, L.; Liu, Y.; Hong, T. Anti-inflammatory effect of epigallocatechin gallate in a mouse model of ovalbumin-induced allergic rhinitis. Int. Immunopharmacol. 2017, 49, 102-108. [CrossRef] [PubMed]

Sample Availability: Samples of the compounds are available from the authors.

(C) 2020 by the authors. Licensee MDPI, Basel, Switzerland. This article is an open access article distributed under the terms and conditions of the Creative Commons Attribution (CC BY) license (http://creativecommons.org/licenses/by/4.0/). 